\title{
Infrared Multiple Photon Dissociation Action Spectroscopy and Theoretical Studies of Diethyl Phosphate Complexes: Effects of Protonation and Sodium Cationization on Structure
}

\author{
B. S. Fales, ${ }^{1}$ N. O. Fujamade, ${ }^{1}$ Y.-w. Nei, ${ }^{1}$ J. Oomens, ${ }^{2,3}$ M. T. Rodgers ${ }^{1}$ \\ ${ }^{1}$ Department of Chemistry, Wayne State University, Detroit, MI 48202, USA \\ ${ }^{2}$ FOM Institute for Plasma Physics "Rijnhuizen", Edisonbaan 14, 3439 MN, Neiuwegein, The Netherlands \\ ${ }^{3}$ van 't Hoff Institute for Molecular Sciences, University of Amsterdam, Amsterdam, The Netherlands
}

\begin{abstract}
The gas-phase structures of deprotonated, protonated, and sodium-cationized complexes of diethyl phosphate $(\mathrm{DEP})$ including $[\mathrm{DEP}-\mathrm{H}]^{-},[\mathrm{DEP}+\mathrm{H}]^{+},[\mathrm{DEP}+\mathrm{Na}]^{+}$, and $[\mathrm{DEP}-\mathrm{H}+2 \mathrm{Na}]^{+}$ are examined via infrared multiple photon dissociation (IRMPD) action spectroscopy using tunable IR radiation generated by a free electron laser, a Fourier transform ion cyclotron resonance mass spectrometer (FT-ICR MS) with an electrospray ionization (ESI) source, and theoretical electronic structure calculations. Measured IRMPD spectra are compared to linear IR spectra calculated at the B3LYP/6-31G(d,p) level of theory to identify the structures accessed in the experimental studies. For comparison, theoretical studies of neutral complexes are also performed. These experiments and calculations suggest that specific geometric changes occur upon the binding of protons and/or sodium cations, including changes correlating to nucleic acid backbone geometry, specifically $\mathrm{P}-\mathrm{O}$ bond lengths and $\angle \mathrm{OPO}$ bond angles. Information from these observations may be used to gain insight into the structures of more complex systems, such as nucleotides and solvated nucleic acids.
\end{abstract}

Key words: Diethyl phosphate, Free electron laser, Infrared multiple photon dissociation, Protons, Sodium cations

\section{Introduction}

$\mathrm{T}$ he transfer of information from generation to generation, a basic requirement for the survival and evolution of a species, is possible only through the existence of nucleic acids in the forms of deoxyribonucleic acid (DNA) and

Electronic supplementary material The online version of this article (doi:10.1007/s13361-010-0007-6) contains supplementary material, which is available to authorized users.

Correspondence to: M. T. Rodgers; e-mail: mrodgers@chem.wayne.edu ribonucleic acid (RNA) [1]. Regulation of the expression and replication of DNA and RNA, the genetic material, is of fundamental importance. One vital form of regulation relies on the concentration of specific metal cations, in particular alkali and alkaline earth metal cations, in the local solvating environment surrounding nucleic acids under physiological conditions [2]. Eichhorn et al. suggest that overstabilization of the negatively charged phosphate backbone by certain metal cations, and in particular magnesium, results in base mispairing. Alkali metal cations, and in particular $\mathrm{Na}^{+}$and $\mathrm{K}^{+}$, are most appreciated for their roles in regulating the electric potential of cells [3]. In addition to these functions, alkali metal 
cations also participate in the regulation of nucleic acids, via relatively weak, noncovalent interactions with the anionic phosphate backbone [4]. Previous theory held that metal cations interact with nucleic acids in a diffuse, fully hydrated cloud, with no direct interaction occurring between counterions and the nucleic acid [5]. Physical evidence contradicting this theory has since become available from NMR spectroscopy [6], X-ray crystallography [7, 8], and molecular dynamics simulations $[9,10]$. These studies clearly refute the previously held counterion condensation theory, showing that metal cations, especially biologically relevant cations including $\mathrm{Na}^{+}, \mathrm{K}^{+}, \mathrm{Mg}^{2+}$, and $\mathrm{Ca}^{2+}$, preferentially bind to specific regions along the phosphate backbone, usually deep within the minor groove. As briefly mentioned, in physiological systems, a hydration sphere accompanies metal cations in the local environment surrounding nucleic acid strands, and its structure has been well characterized [11]. Other hypotheses deny any causal relationship between metal cation interaction along the nucleic acid backbone and conformational changes, suggesting that while cations may exist in these regions, their presence is the effect of induced changes to nucleic acid structure, not the cause [12]. Work reported by Denisov and Halle provides indisputable evidence contrary to these claims, using magnetic relaxation dispersion to demonstrate the preferential binding of sodium cations to the minor groove of AT-rich B-DNA strands [13]. In fact, a strong correlation has been observed between nucleotide sequence and cationbinding tendencies such that AT-rich DNA strands tend to be associated with minor groove cation interactions, while GC-rich strands exhibit major groove cation affinities [14-20]. While there has been some controversy over the roles of metal cations and water molecules, in particular with respect to their mechanisms of interaction and causal relationships with nucleic acid structure, it is generally believed that cations interact directly with both the major and minor grooves of the deprotonated phosphate backbone as counterions, modifying the nucleic acid's structure and reactivity.

In an effort to better understand the underlying mechanisms of these processes, studies of the properties of smaller, related model systems provide information that is helpful in elucidating more general structural and mechanistic information. Previous work from our laboratory using threshold collision-induced dissociation (TCID) techniques was carried out to investigate the thermodynamic properties of metal cation-trimethyl phosphate and metal cation-triethyl phosphate complexes, $\mathrm{M}^{+}$(TMP) and $\mathrm{M}^{+}$(TEP), where $\mathrm{M}^{+}=\mathrm{Na}^{+}$, $\mathrm{K}^{+}, \mathrm{Rb}^{+}, \mathrm{Cs}^{+}, \mathrm{Mg}^{+}, \mathrm{Al}^{+}, \mathrm{Cu}^{+}$, and $\mathrm{Zn}^{+}$[21-23]. These experimental studies were supported and enhanced by theoretical work to allow the visualization of the geometry, energetics, and reaction pathways of each complex of interest. In addition, the binding affinities of each metal cation to the TMP and TEP ligands were determined in an effort to better understand the nature of metal cation binding and its influence on nucleic acid backbone structure and stability. In the TCID studies of the $\mathrm{M}^{+}$(TMP) and $\mathrm{M}^{+}$(TEP) complexes, where $\mathrm{M}^{+}$is an alkali metal cation, only a single dissociation channel was observed, corresponding to the loss of the intact phosphate ester, TMP or TEP. In contrast, CID of $\mathrm{Mg}^{+}-, \mathrm{Al}^{+}-, \mathrm{Cu}^{+}-$, and $\mathrm{Zn}^{+}$-cationized TEP leads to multiple activated dissociation pathways involving cleavage of the phosphate ester bonds, leading to loss of ethene fragments in addition to loss of intact TEP.

Another alkylated phosphate ester, diethyl phosphate (DEP), is a reasonable model of the secondary alkyl phosphate ester linkage of nucleic acid backbones. Study of the infrared multiple photon dissociation (IRMPD) spectroscopy of deprotonated, protonated, and metal-cationized DEP complexes, in conjunction with theoretical linear IR spectra, optimized geometries, and the relative energies of the stable geometries of these ions, is expected to provide important insight into the physical properties of these interactions. The present work is complemented by other studies being pursued in our laboratories, where IRMPD action spectroscopy of protonated and metal-cationized nucleobases and deprotonated, protonated, and metal-cationized mononucleotide-5'-phosphates are being investigated using methods similar to those employed here [24].

\section{Experimental}

\section{General Procedures}

A 4.7 $\mathrm{T}$ Fourier transform ion cyclotron resonance mass spectrometer (FT-ICR MS) coupled to the free electron laser for infrared experiments (FELIX) was used in these experiments, which has previously been described in detail elsewhere [25-28]. Diethyl phosphate was obtained from Sigma-Aldrich. Solutions containing $1 \mathrm{mM}$ DEP were prepared in a 50:50 methanol:water mixture and were used directly to generate deprotonated DEP ions, $[\mathrm{DEP}-\mathrm{H}]^{-}$. Sodiated complexes, $[\mathrm{DEP}-\mathrm{H}+2 \mathrm{Na}]^{+}$and $[\mathrm{DEP}+\mathrm{Na}]^{+}$, were generated by adding $1 \mathrm{mM}$ sodium chloride to the DEP solutions. The intensity of the $[\mathrm{DEP}+\mathrm{Na}]^{+}$generated was significantly enhanced by the acidification of these solutions with $2 \mathrm{mM} \mathrm{HCl}$. Protonated DEP ions, $[\mathrm{DEP}+\mathrm{H}]^{+}$, were generated by adding $2 \mathrm{mM} \mathrm{HCl}$ to the DEP solutions. The DEP solutions were introduced into the mass spectrometer using a Micromass electrospray ionization (ESI) source. Ions were collected for several seconds in a hexapole trap before being transferred into the ICR cell via a quadrupole deflector and an octopole ion guide. Precursor ions were selected using stored waveform inverse Fourier transform (SWIFT) methods prior to irradiation by FEL light. The selected precursor ions were irradiated for 3-4 s over the range extending from $\sim 17.0$ to $5.7 \mu \mathrm{m}\left(\sim 590\right.$ to $\left.1750 \mathrm{~cm}^{-1}\right)$. The IRMPD fragmentation of [DEP $-\mathrm{H}]^{-}$and $[\mathrm{DEP}+\mathrm{H}]^{+}$was efficient enough that irradiation for only $3 \mathrm{~s}$ at $3 \mathrm{~dB}$ attenuation was necessary, while the sodiated complexes, $[\mathrm{DEP}-\mathrm{H}+2 \mathrm{Na}]^{+}$and $[\mathrm{DEP}+\mathrm{Na}]^{+}$, required $4 \mathrm{~s}$ of irradiation at full power to produce IRMPD spectra of similar quality $(\mathrm{S} / \mathrm{N})$. The relatively low IRMPD intensity observed for the $[\mathrm{DEP}+\mathrm{Na}]^{+}$complex is likely the result of 
mass discrimination in the detection of the low $m / z 23 \mathrm{Na}^{+}$ product.

\section{Theoretical Calculations}

Representative model structures were obtained for each of the experimental systems and for two additional neutral systems using simulated annealing molecular mechanics procedures and ab initio calculations. Potential low-energy candidate structures were obtained via a 300 cycle annealing process using HyperChem (C [29] software. A three-phase annealing process was used, with each cycle beginning and ending at $0 \mathrm{~K}$, lasting for $0.8 \mathrm{ps}$, and achieving a simulation temperature of $1000 \mathrm{~K}$. Heating and cooling times for each cycle were $0.3 \mathrm{ps}$ each, allowing $0.2 \mathrm{ps}$ for the complex to sample conformational space at the simulation temperature. Relative energies were computed using molecular mechanics methods every $0.001 \mathrm{ps}$, and the most stable conformers accessed at the end of each annealing cycle were subjected to additional analysis. For each complex, 7-25 of the most stable conformers were further investigated using density functional theory (DFT) methods. Geometry optimizations, frequency analyses, and single point energy calculations were performed using the Gaussian 03 suite of programs [30]. Initial optimizations were performed at the B3LYP/6$31 \mathrm{G}(\mathrm{d})$ level of theory. However, calculations using a larger basis set, B3LYP/6-31G(d,p), were found to provide slightly improved agreement with the experimental IRMPD spectroscopic data. In many cases, the band positions of the spectral features were unaffected by using the slightly larger basis set, but in other cases small shifts on the order of $10-15 \mathrm{~cm}^{-1}$ were observed. For example, the feature at $953 \mathrm{~cm}^{-1}$ in the IR spectrum of $[\mathrm{DEP}+\mathrm{H}]^{+}$redshifts to $940 \mathrm{~cm}^{-1}$, corresponding to the band at $910 \mathrm{~cm}^{-1}$ in the experimental IRMPD spectrum. Similarly, the band at $1233 \mathrm{~cm}^{-1}$ in the IR spectrum of $[\mathrm{DEP}+\mathrm{Na}]^{+}$blue shifts to $1240 \mathrm{~cm}^{-1}$, in excellent agreement with the band at $1240 \mathrm{~cm}^{-1}$ in the measured IRMPD spectrum. In contrast, the use of the $6-31 \mathrm{G}(\mathrm{d}, \mathrm{p})$ basis set resulted in negligible changes in the relative energetics of the various stable conformers computed. A frequency-scaling factor of 0.9613 , as suggested by Wong [31], was used for the [DEH $-\mathrm{H}]^{-}$ ions. In contrast, the best fits to the experimental results for the $[\mathrm{DEP}+\mathrm{H}]^{+},[\mathrm{DEP}+\mathrm{Na}]^{+}$, and $[\mathrm{DEP}-\mathrm{H}+2 \mathrm{Na}]^{+}$were found when the frequencies were unscaled. These observations are consistent with work done by others, including Correia et al., where vibrational stretching modes corresponding to protonated phosphate groups are calculated to be redshifted with respect to the experimental values after a suggested (0.9613) scaling factor is applied [32]. The theoretical linear IR spectra were broadened using a $30 \mathrm{~cm}^{-1}$ Gaussian line shape to account for quantum harmonic effects and to allow for meaningful comparison to the experimental spectra. Single point energy calculations were carried out at the B3LYP, B3P86, and MP2(full) levels of theory using the $6-311+G(2 d, 2 p)$ basis set. Energetic data include zero point energy (ZPE) corrections for the single point energy calculations and Gibbs energy corrections for the free energy values (based on the frequency calculations at the B3LYP/6-31 $\mathrm{G}(\mathrm{d}, \mathrm{p})$ level). The ground-state structure of each complex was determined by comparing the relative energies of each of the stable conformers computed, taking the lowest energy structure as that of the ground state.

\section{Results}

\section{IRMPD Action Spectra}

Determination of the experimental spectra was accomplished through the calculation of the IRMPD yield following ion exposure to FEL light, as depicted in Equation (1):

$$
\operatorname{IRMPD} \text { yield }=\left(\Sigma I_{\mathrm{f}}\right) /\left(I_{\mathrm{p}}+\Sigma I_{\mathrm{f}}\right),
$$

where $I_{\mathrm{f}}$ is the fragment ion intensity and $I_{\mathrm{p}}$ is the precursor ion intensity. Williams and coworkers have recently suggested that the use of a first-order laser-induced photodissociation rate constant, which is proportional to the total fragment ion intensity, in lieu of the photodissociation yield method used here may be advantageous for comparison to theoretical linear IR spectra [33]. Therefore, we also compared the measured IRMPD action spectra computed based on the total fragment ion intensities to the theoretical linear IR spectra. In all cases, the relative intensities of the spectral features in the computed spectra exhibited better agreement with the IRMPD yields than the IRMPD intensities, clearly indicating the multiphoton nature of the dissociation processes examined here. Thus, the IRMPD yields were used throughout. Experimental IRMPD action spectra for each of the four systems investigated are presented in Figure 1. While data were collected over the range from $\sim 590$ to $1750 \mathrm{~cm}^{-1}$, no spectral features were observed below $650 \mathrm{~cm}^{-1}$ or above $1400 \mathrm{~cm}^{-1}$, and thus the data are only shown over this range of frequencies. Bands are well resolved in each spectrum, with excellent signal to noise. IRMPD dissociation of each ion resulted in the loss of a neutral fragment and the detection of the corresponding fragment ion.

The spectrum produced from the dissociation of the [DEP $-\mathrm{H}]^{-}$ions exhibits four distinct, high-intensity bands at $715,900,1080$ and $1280 \mathrm{~cm}^{-1}$ as well as a lowintensity band at $1370 \mathrm{~cm}^{-1}$. Evidence of splitting of the band at $1080 \mathrm{~cm}^{-1}$ is apparent in the measured spectrum, suggesting the coupling of two related stretching modes. The deprotonated [DEP $-\mathrm{H}]^{-}$ions experience the loss of ethene, yielding the deprotonated monoethyl phosphate anion (MEP-H) ${ }^{-}$with an $\mathrm{m} / \mathrm{z}$ ratio of 125 . In addition, the loss of a second ethene molecule with the concomitant loss of water produces the inorganic metaphosphate anion, $\mathrm{PO}_{3}{ }^{-}$, at $\mathrm{m} / \mathrm{z}$ 79. Alternatively, the metaphosphate anion may be produced by the sequential loss of ethanol from the primary $[\mathrm{MEP}-\mathrm{H}]^{-}$fragment ion. Additional experiments to probe the true nature of this loss were not pursued. 


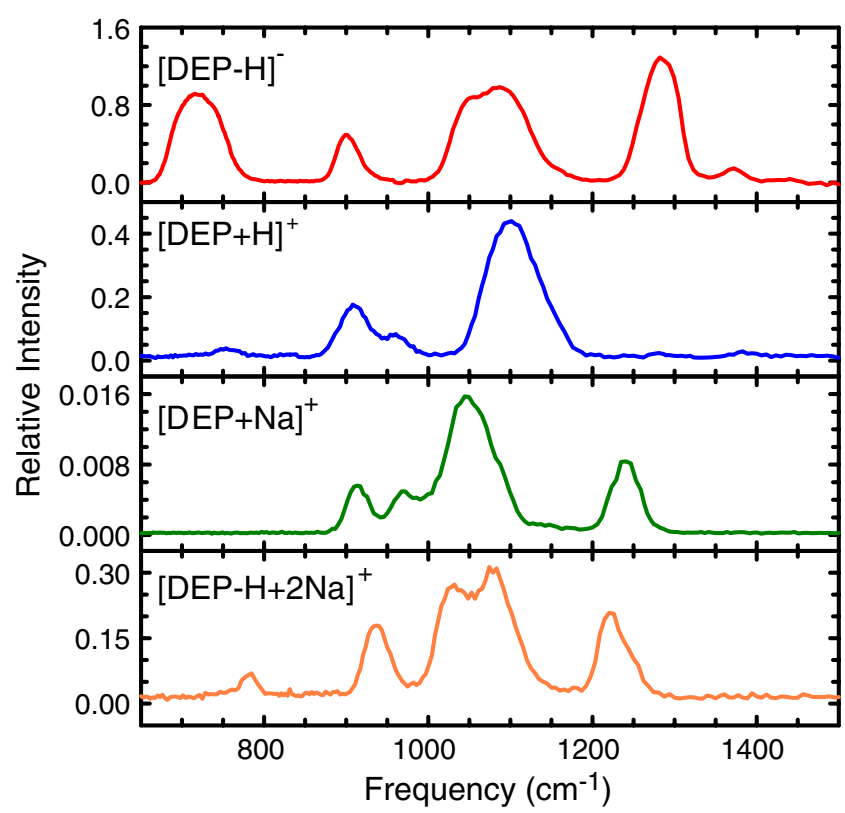

Figure 1. Infrared multiple photon dissociation action spectra of the $[\mathrm{DEP}-\mathrm{H}]^{-},[\mathrm{DEP}+\mathrm{H}]^{+},[\mathrm{DEP}+\mathrm{Na}]^{+}$, and $[\mathrm{DEP}-\mathrm{H}+2 \mathrm{Na}]^{+}$ complexes

IRMPD of protonated DEP ions, [DEP $+\mathrm{H}]^{+}$, produced the simplest spectrum observed in this study. Only three major bands were observed, at 910,960, and $1100 \mathrm{~cm}^{-1}$. The intensity of the band at $1100 \mathrm{~cm}^{-1}$ is three times that of the band at $910 \mathrm{~cm}^{-1}$, and approximately six times that of the band at $960 \mathrm{~cm}^{-1}$. In addition to these distinct spectral features, a small band at $750 \mathrm{~cm}^{-1}$ is observed whose intensity is fifteen times less than that of the high-intensity band at $1100 \mathrm{~cm}^{-1}$. While the intensity of the $750 \mathrm{~cm}^{-1}$ band is relatively low, this feature is sufficiently well resolved to warrant inclusion for the purposes of conformer assignment and identification. Three discrete fragmentation channels were observed upon photoactivation of the $[\mathrm{DEP}+\mathrm{H}]^{+}$ions, resulting in the formation of ionic products at $\mathrm{m} / \mathrm{z} 127$ (corresponding to the loss of neutral ethene), at $\mathrm{m} / \mathrm{z} 99$ (loss of two neutral ethene molecules), and at $\mathrm{m} / \mathrm{z} 81$ (loss of either two ethenes and one water molecule, or the loss of one ethene and one ethanol molecule). Again, experiments to probe the true nature of the latter loss were not pursued.

Four major bands at 915, 970,1045, and $1240 \mathrm{~cm}^{-1}$ were observed in the IRMPD action spectrum of the [DEP $+\mathrm{Na}]^{+}$ complex. The band at $970 \mathrm{~cm}^{-1}$ appears as a shoulder of the high-intensity band at $1045 \mathrm{~cm}^{-1}$, but is resolved well enough to be considered a distinct band. The intensity of the band at $1045 \mathrm{~cm}^{-1}$ is $2-3$ times greater than that of any of the other bands observed. Only one dissociation channel was observed for the [DEP $+\mathrm{Na}]^{+}$ions: loss of the intact neutral ligand to produce $\mathrm{Na}^{+}$.

The $[\mathrm{DEP}-\mathrm{H}+2 \mathrm{Na}]^{+}$ions produced the most featurerich spectrum of the systems investigated here. Bands at 785, $935,1030,1080$, and $1220 \mathrm{~cm}^{-1}$ are well defined, and some coupling appears between the high-intensity bands at 1030 and $1080 \mathrm{~cm}^{-1}$. Bands at 935 and $1220 \mathrm{~cm}^{-1}$ are similar in intensity to one another, but only half the intensity of the bands at 1030 and $1080 \mathrm{~cm}^{-1}$. The $785 \mathrm{~cm}^{-1}$ band has an intensity that is five times less than those of the high-intensity bands. Photoactivation of [DEP $-\mathrm{H}+2 \mathrm{Na}]^{+}$ions was observed to occur through three major dissociation channels. Similar to the other complexes, loss of ethene is observed at $\mathrm{m} / \mathrm{z} 171$, as well as the loss of two molecules of ethene and a single water molecule (or the loss of ethene and ethanol) at $\mathrm{m} / \mathrm{z}$ 125. In addition, a third channel where the loss of [DEP $-\mathrm{H}+\mathrm{Na}$ ] occurs to produce $\mathrm{Na}^{+}$at $m / z 23$ is also observed.

\section{Theoretical Results}

A total of six molecular systems, both ionic ([DEP $-\mathrm{H}]^{-}$, $[\mathrm{DEP}+\mathrm{H}]^{+}$, and $\left.[\mathrm{DEP}-\mathrm{H}+2 \mathrm{Na}]^{+}\right)$and neutral $([\mathrm{DEP}]$ and [DEP - H - Na]), were investigated using electronic structure methods, as described in the "Theoretical Calculations" section. Geometry optimizations and frequency analyses at the B3LYP/6-31G(d,p) level of theory were performed for each of these species, and the corresponding linear IR spectra were determined for comparison to the experimental IRMPD action spectra. The relative energies at $0 \mathrm{~K}$ and free energies at $298 \mathrm{~K}$ of the most stable conformers found for each system at the B3LYP, B3P86, and MP2(full) levels of theory using a $6-311+\mathrm{G}(2 \mathrm{~d}, 2 \mathrm{p})$ basis set are summarized in Table 1. The absolute relative stabilities of the stable low-energy conformers computed for each system differ somewhat depending on the level of theory employed and are generally within $\sim 2 \mathrm{~kJ} / \mathrm{mol}$, but in all cases are less than $3.4 \mathrm{~kJ} / \mathrm{mol}$ such that the trends in

Table 1. Relative energies at $0 \mathrm{~K}$ and free energies at $298 \mathrm{~K}$ of low-energy geometries of DEP complexes ${ }^{\mathrm{a}}$

\begin{tabular}{|c|c|c|c|c|c|c|c|}
\hline \multirow[t]{2}{*}{ Species } & \multirow[t]{2}{*}{ Conformer } & \multicolumn{2}{|c|}{ B3LYP } & \multicolumn{2}{|c|}{ B3P86 } & \multicolumn{2}{|c|}{ MP2(full) } \\
\hline & & $\Delta \mathrm{H}_{0}$ & $\Delta \mathrm{G}_{298}$ & $\Delta \mathrm{H}_{0}$ & $\Delta \mathrm{G}_{298}$ & $\Delta \mathrm{H}_{0}$ & $\Delta \mathrm{G}_{298}$ \\
\hline \multirow[t]{5}{*}[\mathrm{DEP}-\mathrm{H}]{$^{-}$} & $\mathrm{C} 1$ & 0.0 & 0.0 & 0.0 & 0.0 & 0.0 & 0.0 \\
\hline & $\mathrm{C} 2$ & 2.4 & 5.6 & 1.5 & 4.8 & 0.6 & 3.8 \\
\hline & C3 & 3.4 & 6.6 & 2.8 & 5.9 & 1.8 & 4.9 \\
\hline & $\mathrm{C} 4$ & 5.4 & 4.9 & 5.7 & 5.2 & 7.2 & 6.7 \\
\hline & C5 & 8.5 & 9.5 & 8.0 & 9.0 & 9.1 & 10.1 \\
\hline \multirow[t]{3}{*}{ [DEP] } & $\mathrm{C} 1$ & 0.0 & 0.0 & 0.0 & 0.0 & 0.0 & 0.0 \\
\hline & $\mathrm{C} 2$ & 2.7 & 1.1 & 2.6 & 1.0 & 2.1 & 1.1 \\
\hline & $\mathrm{C} 3$ & 3.2 & 5.4 & 3.3 & 5.5 & 2.7 & 4.3 \\
\hline \multirow{3}{*}[\mathrm{DEP}+\mathrm{H}]{$^{+}$} & $\mathrm{C} 1$ & 0.0 & 0.0 & 0.0 & 0.0 & 0.0 & 0.0 \\
\hline & $\mathrm{C} 2$ & 9.6 & 6.0 & 9.4 & 5.9 & 9.6 & 6.0 \\
\hline & C3 & 13.3 & 11.2 & 12.7 & 10.6 & 11.4 & 9.3 \\
\hline \multirow[t]{3}{*}[\mathrm{DEP}-\mathrm{H}+\mathrm{Na}]{} & B1 & 0.0 & 0.0 & 0.0 & 0.0 & 0.0 & 0.0 \\
\hline & B2 & 27.9 & 27.6 & 28.9 & 28.5 & 28.0 & 27.7 \\
\hline & $\mathrm{T} 1$ & 36.6 & 35.7 & 36.5 & 35.7 & 33.2 & 32.3 \\
\hline \multirow[t]{3}{*}[\mathrm{DEP}+\mathrm{Na}]{$^{+}$} & B1 & 0.0 & 0.0 & 0.0 & 0.0 & 0.0 & 0.0 \\
\hline & B2 & 0.1 & 0.1 & 0.1 & 0.1 & 0.1 & 0.1 \\
\hline & B3 & 4.2 & 8.2 & 3.8 & 7.9 & 2.2 & 6.3 \\
\hline \multirow[t]{3}{*}[\mathrm{DEP}-\mathrm{H}+2\mathrm{Na}]{$^{+}$} & BB1 & 1.8 & 2.2 & 1.6 & 1.9 & 0.0 & 0.0 \\
\hline & BB2 & 0.0 & 0.0 & 0.0 & 0.0 & 0.5 & 0.2 \\
\hline & BB3 & 22.3 & 19.8 & 22.4 & 19.8 & 20.4 & 17.5 \\
\hline
\end{tabular}

${ }^{\text {a }}$ Energetics determined from single point energies calculated using a $6-311+\mathrm{G}$ $(2 \mathrm{~d}, 2 \mathrm{p})$ basis set and structures optimized at the B3LYP/6-31G(d,p) level of theory including zero point energy corrections. All energies given are in $\mathrm{kJ} / \mathrm{mol}$. 
the relative stabilities are highly parallel for all three theories examined. Only in the case of the $[\mathrm{DEP}-\mathrm{H}+2 \mathrm{Na}]^{+}$complex do these differences suggest a different structure for the ground-state conformation. B3LYP and B3P86 suggest that the $\mathrm{BB} 2$ conformer is the ground state, while MP2 suggests the BB1 conformer. Based upon comparison of the computed IR spectra and the measured IRMPD spectrum, MP2 appears to provide more reliable results in this case. Thus, the following discussion focuses on the MP2 results.

Due to the relative simplicity of each of the systems lacking a metal cation, $[\mathrm{DEP}-\mathrm{H}]^{-}$, [DEP], and $[\mathrm{DEP}+\mathrm{H}]^{+}$, the potential energy surfaces are relatively unremarkable and multiple low-energy conformers (within $\sim 10 \mathrm{~kJ} / \mathrm{mol}$ of the ground state) are present for each system. Each of these conformers differs solely in the spatial arrangement of the alkoxy, hydroxyl, and oxo functional groups surrounding the central phosphate atom. The corresponding vibrational spectra are very similar, and in places are nearly indiscernible from one another. Only small differences are visible in the relative intensities of the major bands, with minimal or negligible shifts in their frequencies. The overall shapes of both individual bands, as well as the overall spectrum, allow definitive characterization and assignment of each system based on the observed spectral features. This is in stark contrast to the sodium-containing complexes, where large energy differences arise from different binding modes of the metal cation to the ligand, resulting in significantly more well-defined potential energy surfaces. The theoretical spectra of the various stable conformers of the sodiated complexes are unique and exhibit noticeable variations in both the relative intensities of the bands and their frequency distributions.

\section{$[D E P-H]^{-}$}

Each of the five anionic structures depicted in Figure 2 (labeled C1-C5 for conformers 1-5), and shown in more detail in the Electronic Supplemental Material (ESM) Figure 1S, exhibit only minor variation in side chain geometry, resulting in relatively small differences in energies between the ground-state structure and the stable lowenergy conformers. In each case, the oxygen atoms surround the central phosphate atom in a nearly tetrahedral arrangement, and one of the alkoxy side chains is oriented down and away from the adjacent oxo moiety. In the ground-state structure, the second alkoxy group is staggered away from the first alkoxy group, and is also oriented away from the adjacent oxo moiety. The other conformers found arise as a result of rotation of the second alkoxy side chain about the $\angle$ POCC dihedral angle, producing steric repulsion and increasing the relative energies of these conformers.

\section{[DEP]}

Similar to the deprotonated $[\mathrm{DEP}-\mathrm{H}]^{-}$species, neutral [DEP] exhibits several closely related potential energy wells

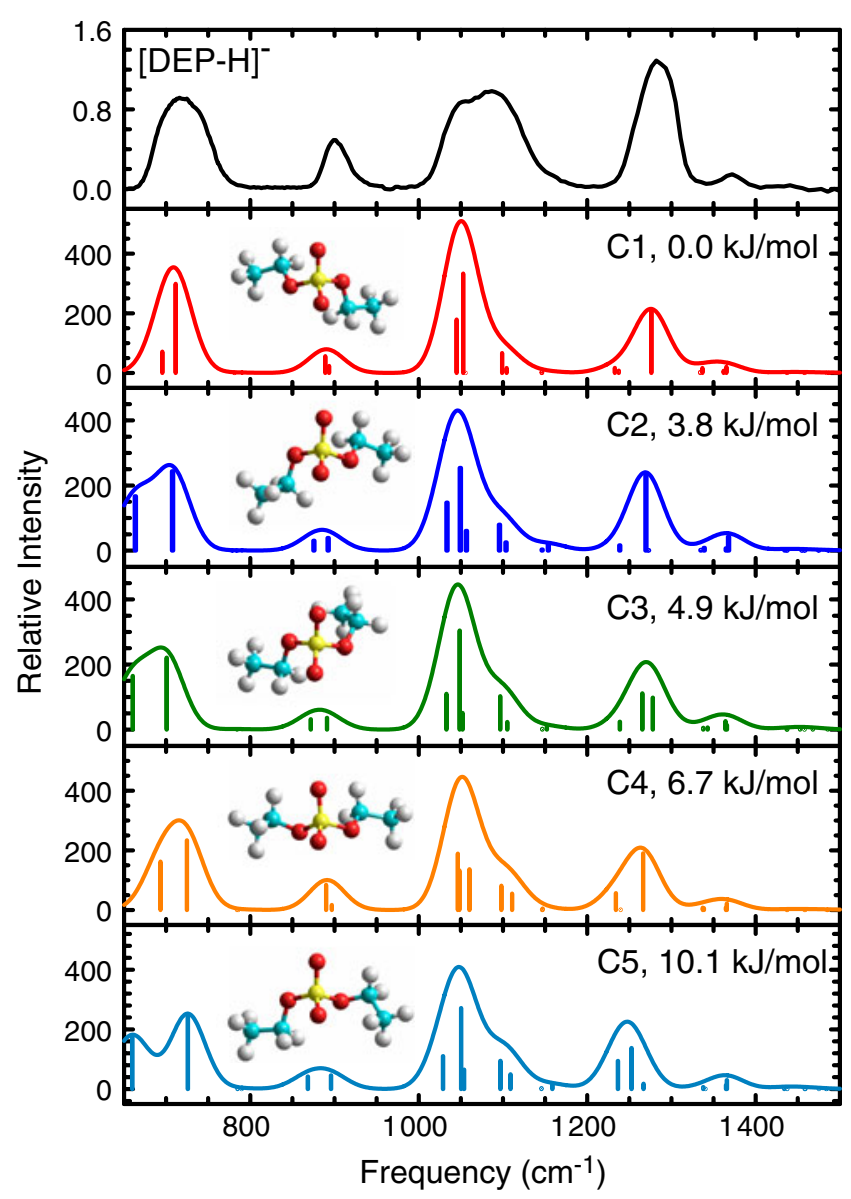

Figure 2. Comparison of the measured IRMPD action spectrum of [DEP $-\mathrm{H}]^{-}$with the linear IR spectra predicted for the five most stable conformers of [DEP $-\mathrm{H}]^{-}$at the B3LYP/6-31G(d,p) level of theory. The structures and MP2 (full) $/ 6-311+G(2 d, 2 p)$ relative free energies of the conformers are also shown

corresponding to rotation of the alkoxy side chains about the $\angle$ POCC dihedral angle. The three structures shown in ESM Figures $2 \mathrm{~S}$ and $3 \mathrm{~S}$, labeled $\mathrm{C} 1-\mathrm{C} 3$ (conformers 1-3), differ by less than $4.3 \mathrm{~kJ} / \mathrm{mol}$ (MP2). Thus, all three conformers are likely accessed at room temperature.

\section{$[D E P-H+N a]$}

Binding of a sodium cation to the deprotonated phosphate ester markedly affects the potential energy landscape. Only one lowenergy candidate was found. All other stable minima computed lie relatively high in energy, $\sim 27-37 \mathrm{~kJ} / \mathrm{mol}$ above the groundstate structure. Each structure is depicted in ESM Figures $4 \mathrm{~s}$ and 5S. In the ground-state structure, labeled B1 (bidentate 1), the sodium cation interacts in a bidentate fashion with both oxo groups of the deprotonated phosphate ester ligand. One alkoxy chain is staggered out and away from the sodium dioxo region, while the other alkoxy chain is oriented down and away from the oxo groups. A much less favorable conformer, B2, exists where the sodium cation interacts with one oxo and one alkoxy 
oxygen atom, forming a bidentate complex that lies $27.7 \mathrm{~kJ} / \mathrm{mol}$ (MP2) higher in free energy than the ground-state conformer. Still less favorable is a tridentate complex, T1, where the sodium cation binds to two alkoxy oxygen atoms and one of the oxo moieties. This system lies $32.3 \mathrm{~kJ} / \mathrm{mol}$ (MP2) above the ground-state structure.

\section{$[D E P+H]^{+}$}

Protonated DEP structures show little variation in spatial arrangement, and are depicted in Figure 3 and ESM Figure 6S. The ground-state structure, denoted $\mathrm{C} 1$, has fully staggered alkoxy side chains. Rotation about the $\angle \mathrm{POCC}$ dihedral angle of an alkoxy side chain by $\sim 90^{\circ}$ produces the C2 structure at a free energy cost of $6.0 \mathrm{~kJ} / \mathrm{mol}$ (MP2). Subsequent rotation of the remaining alkoxy side chain about the same $\angle \mathrm{POCC}$ dihedral angle by $\sim 180^{\circ}$ produces the $\mathrm{C} 3$ structure. The $\mathrm{C} 3$ structure lies $9.3 \mathrm{~kJ} / \mathrm{mol}$ (MP2) above the ground-state conformation.

\section{$[\mathrm{DEP}+\mathrm{Na}]^{+}$}

Each of the stable structures computed for $[\mathrm{DEP}+\mathrm{Na}]^{+}$ involves the sodium cation binding to the neutral DEP ligand in a bidentate fashion. The measured IRMPD action spectrum, and the structures of the three low-energy conformers and their computed linear IR spectra, are shown in Figure 4. ESM Figure 7S depicts each structure in greater

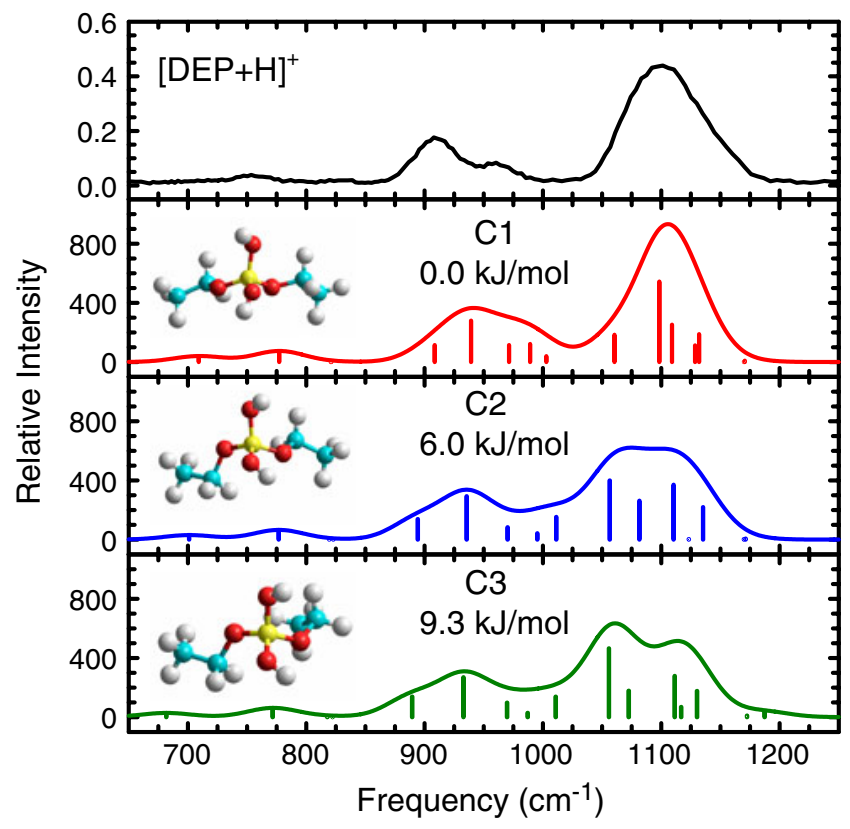

Figure 3. Comparison of the measured IRMPD action spectrum of $[\mathrm{DEP}+\mathrm{H}]^{+}$with the linear IR spectra predicted for the three most stable conformers of $[\mathrm{DEP}+\mathrm{H}]^{+}$at the B3LYP/6-31G(d,p) level of theory. The structures and MP2 (full) $/ 6-311+G(2 d, 2 p)$ relative free energies of each conformer are also shown

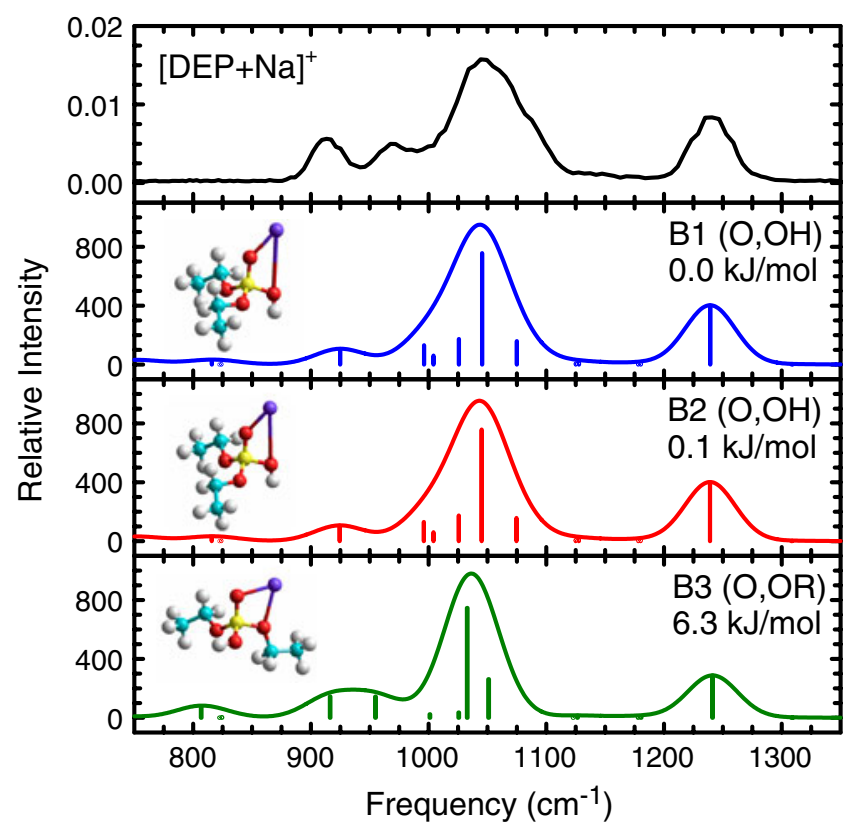

Figure 4. Comparison of the measured IRMPD action spectrum of $[\mathrm{DEP}+\mathrm{Na}]^{+}$with the linear IR spectra predicted for the three most stable conformers of $[\mathrm{DEP}+\mathrm{Na}]^{+}$at the B3LYP/6-31G(d,p) level of theory. The structures and MP2 (full)/ $6-311+G(2 d, 2 p)$ relative free energies of each conformer are also shown

detail, including relative energies and $\mathrm{Na}^{+}-\mathrm{O}$ bond distances. In the predicted ground-state conformer, B1, the sodium cation binds to the oxo and hydroxyl oxygen atoms, while the alkoxy groups are fully staggered. The B2 structure also involves bidentate interaction of the sodium cation with the oxo and hydroxyl oxygen atoms, and is virtually identical to B1 except that the $\mathrm{Na}^{+}-\mathrm{O}$ bond distance is slightly shorter (by $0.02 \AA$ ). The B2 conformer is calculated to be a mere $0.1 \mathrm{~kJ} / \mathrm{mol}$ (MP2) higher in free energy than the ground-state B1 conformer. The B3 structure differs from the B1 and B2 structures in that the sodium cation binds to the oxo and one of the alkoxy oxygen atoms. This arrangement forces the participating alkoxy group to become oriented down and away from the sodium cation, while the other alkoxy group remains staggered. The sodium cation-alkoxy oxygen distance is significantly reduced as compared to the sodium cation-hydroxyl oxygen distances in the B1 and B2 structures. The B3 conformer is calculated to lie $6.3 \mathrm{~kJ} / \mathrm{mol}$ (MP2) above the ground-state B1 conformer. Rotation of the remaining alkoxy group results in significant steric repulsion and destabilization of the corresponding conformers.

$[D E P-H+2 N a]^{+}$

The disodiated complex of deprotonated DEP, [DEP $-\mathrm{H}+$ $2 \mathrm{Na}]^{+}$, exhibits the greatest structural variation amongst the systems studied here. The measured IRMPD action spectrum and the structures of the three low-energy conformers and their computed linear IR spectra are shown in Figure 5. ESM 


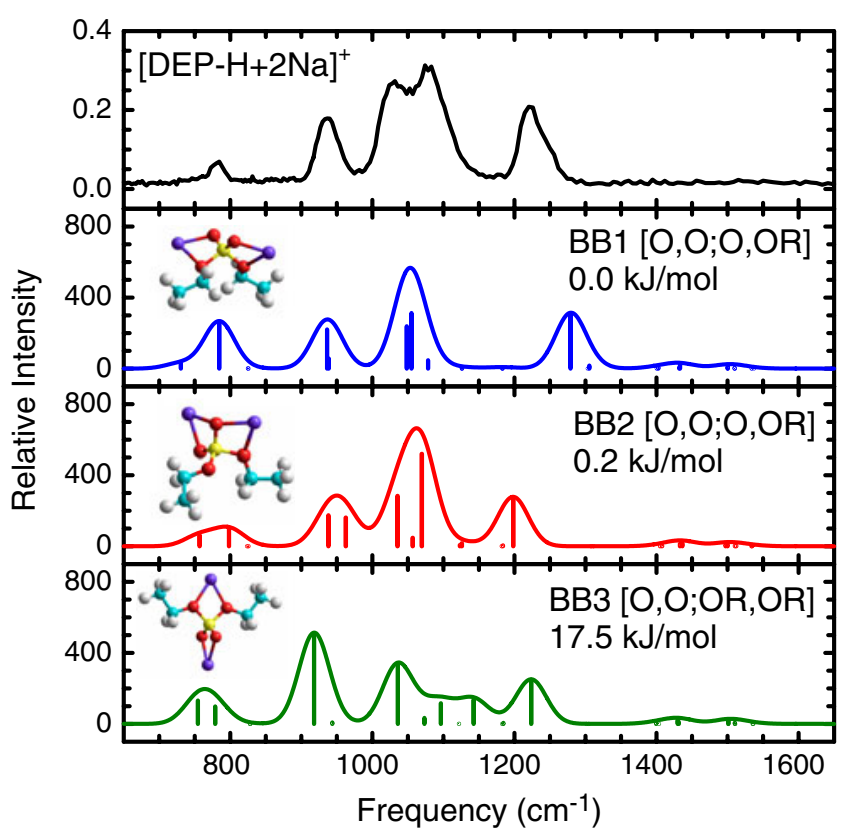

Figure 5. Comparison of the measured IRMPD action spectrum of $[\mathrm{DEP}-\mathrm{H}+2 \mathrm{Na}]^{+}$with the linear IR spectra predicted for the three most stable conformers of [DEP $-\mathrm{H}+$ $2+\mathrm{Na}^{+}$at the B3LYP/6-31G(d,p) level of theory. The structures and MP2(full)/6-311+G(2d,2p) relative stabilities of each conformer are also shown

Figure 8S depicts detailed structural information for these stable conformers. Both sodium cations participate in a bidentate interaction with the phosphate ester oxygen atoms. In the ground-state structure, labeled BB1 (bidentate-bidentate), each sodium cation interacts with one oxo and one of the alkoxy oxygen atoms. The alkoxy chains are staggered with respect to one another and are rotated away from the adjacent sodium cations. The BB2 conformer is the least symmetrical of the three low-energy conformers computed. In the BB2 conformer, one sodium cation interacts with both available oxo moieties, while the other sodium cation binds to an oxo and an alkoxy oxygen atom. The participating alkoxy chain is rotated down and away from the sodium cation, while the other alkoxy chain remains staggered about the near-tetrahedral phosphate. The BB2 conformer lies $0.2 \mathrm{~kJ} / \mathrm{mol}$ (MP2) higher in free energy than the ground-state structure. In contrast, both B3LYP and B3P86 suggest that the $\mathrm{BB} 2$ conformer is favored over the $\mathrm{BB} 1$ conformer by $\sim 2 \mathrm{~kJ} / \mathrm{mol}$. The BB3 conformer exhibits the greatest symmetry, but is also the least stable of the three conformers. One sodium cation interacts with both oxo moieties, while the other sodium cation interacts with both alkoxy oxygen atoms. The resulting electrostatic repulsion and steric interactions present in this system lead to the BB3 conformation being $17.5 \mathrm{~kJ} / \mathrm{mol}$ less stable (MP2) than the ground-state conformation.

\section{Discussion}

When comparing experimental IRMPD spectra with the theoretical spectra, it is important to note that the theoretical methods produce linear IR spectra (single photon absorption), while the experimental data reflect multiple photon absorption by the precursor ion. As a result, the band positions are generally reproduced quite well, but the relative intensities of the various bands may or may not be as a consequence of variations in anharmonic coupling/ shifting and the resulting differences in multiple-photon excitation efficiencies. When comparing the measured IRMPD spectrum to the theoretical IR spectra for various low-energy conformers, anharmonic effects-when they occur - are expected to be highly parallel for species when the nature of the covalent bonding and noncovalent interactions are similar, but may differ when the nature of the bonding or noncovalent interactions differ markedly.

\section{$[D E P-H]^{-}$}

The measured IRMPD action spectrum is compared to the linear IR spectra of the five most energetically favorable conformers computed for the [DEP $-\mathrm{H}]^{-}$complex in the 650-1500 $\mathrm{cm}^{-1}$ range in Figure 2. Examination of the spectra reveals that the theoretical spectra for all five lowenergy conformers match the experimental spectrum reasonably well, but the best agreement is seen for the ground-state $\mathrm{C} 1$ and third excited state $\mathrm{C} 4$ conformers. The highest intensity bands, at 1080 and $1280 \mathrm{~cm}^{-1}$, represent symmetric and asymmetric $\mathrm{P}=\mathrm{O}$ stretches, respectively. Another relatively high intensity band at $715 \mathrm{~cm}^{-1}$ corresponds to asymmetric $\mathrm{P}-\mathrm{O}$ stretching. Lower intensity bands, at 900 and $1374 \mathrm{~cm}^{-1}$, correspond to asymmetric $\mathrm{P}-\mathrm{O}-\mathrm{C}$ alkoxy stretching and asymmetric $\mathrm{C}-\mathrm{C}$ stretching, respectively.

\section{$[D E P+H]^{+}$}

The experimental IRMPD action spectrum for the [DEP + $\mathrm{H}]^{+}$system is compared to the theoretical linear IR spectra for the three lowest energy conformers found in Figure 3. The spectrum of the ground-state structure, $\mathrm{C} 1$, provides an excellent match to the experimental action spectrum. The high-intensity band at $1100 \mathrm{~cm}^{-1}$ represents both symmetric and asymmetric $\mathrm{P}-\mathrm{O}$ alkoxy stretching. A group of lower intensity bands between 910 and $960 \mathrm{~cm}^{-1}$ represent symmetric $\mathrm{P}-\mathrm{O}$ hydroxyl stretching and hydroxyl wagging. The relative intensities of the theoretical bands differ slightly from the experimental spectrum in this region, which may be the result of differences between linear absorption and multiple-photon dissociation, as mentioned above. A very weak band was also observed at $750 \mathrm{~cm}^{-1}$, representing both asymmetric and symmetric $\mathrm{C}-\mathrm{O}$ alkoxy stretching. The theoretical spectra exhibit two discrete bands describing these stretches, at 710 and $770 \mathrm{~cm}^{-1}$.

Comparison of the experimental IRMPD spectrum to each of the three calculated spectra suggests that the theoretical $\mathrm{C} 1$ structure is the sole conformation present in the experiments. The shapes of the spectral features and their relative intensities support this conclusion. Assignment of 
the $\mathrm{C} 1$ structure is also supported by energetics predicted by theory. Conformers C2 and C3 lie 6.0 and $9.3 \mathrm{~kJ} / \mathrm{mol}$ (MP2) higher in free energy than the ground-state conformer C1, making them unlikely or very minor contributors to the measured spectrum.

Similar to the $[\mathrm{DEP}-\mathrm{H}]^{-}$system, the structures of each of the potential conformers contributing to the $[\mathrm{DEP}+\mathrm{H}]^{+}$ spectrum differ only in the spatial arrangement and staggering of the alkoxy groups. As expected, the ground-state structure adopts a fully staggered conformation, minimizing steric repulsion between adjacent atoms. The relative stabilities of conformers $\mathrm{C} 2$ and $\mathrm{C} 3$ decrease as a result of steric interactions. Based on the computed energetics, these latter conformers are unlikely to be appreciably populated at room temperature.

\section{$[\mathrm{DEP}+\mathrm{Na}]^{+}$}

Figure 4 compares the experimental IRMPD action spectrum of the $[\mathrm{DEP}+\mathrm{Na}]^{+}$complex and the theoretical linear IR spectra of the three low-energy conformers computed. The high-intensity band observed at $1045 \mathrm{~cm}^{-1}$ corresponds to asymmetric and symmetric $\mathrm{P}-\mathrm{O}-\mathrm{C}$ alkoxy stretching. A second high-intensity band at $1240 \mathrm{~cm}^{-1}$ represents $\mathrm{P}=\mathrm{O}$ stretching. Each of these experimental bands corresponds extremely well with the theoretical spectra such that no assumptions regarding likely conformers present can be made using these data alone. Lower intensity bands at 915 and $970 \mathrm{~cm}^{-1}$ represent $\mathrm{P}-\mathrm{O}$ hydroxyl stretching modes, with the $970 \mathrm{~cm}^{-1}$ band also representing symmetric $\mathrm{P}-\mathrm{O}-\mathrm{C}$ alkoxy stretching. Comparison of the theoretical spectra to the experimental action spectrum suggests that the B1 and B2 conformers are the major contributors to the experimental spectrum, with minor contributions from the B3 conformer. This conclusion is supported by the shape and location of the spectral features as well as by the predicted energetics. Because the B1 and B2 conformers are predicted to lie within $0.1 \mathrm{~kJ} / \mathrm{mol}$ of each other, both are expected to be present in nearly equal populations in the experiments. The band in the $970 \mathrm{~cm}^{-1}$ region suggests the presence of the B3 conformer.

\section{$[D E P-H+2 N a]^{+}$}

Figure 5 compares the experimental IRMPD action spectrum and the theoretical linear IR spectra for the three low-energy conformers of the $[\mathrm{DEP}-\mathrm{H}+2 \mathrm{Na}]^{+}$complexes found. The high-intensity band at $1055 \mathrm{~cm}^{-1}$ represents symmetric and asymmetric $\mathrm{O}-\mathrm{C}$ alkoxy stretching, symmetric $\mathrm{P}=\mathrm{O}$ stretching, and free $\mathrm{P}-\mathrm{O}-\mathrm{C}$ alkoxy stretching. Splitting of this band in the experimental spectrum can be attributed to coupling of the alkoxy and oxo stretching modes. This band is the most diagnostic for the BB1 and BB2 conformers based on the general shape and splitting of this feature. A high-intensity band at $1225 \mathrm{~cm}^{-1}$ represents $\mathrm{P}=\mathrm{O}$ stretching. The prominent shoulder on the high-frequency side of this peak again suggests contributions from both the BB1 and BB2 conformers to the experimental spectrum. The band at $943 \mathrm{~cm}^{-1}$, representing $\mathrm{P}-\mathrm{O}-\mathrm{C}$ alkoxy stretching, also confirms that the BB1 conformer is the major contributor, while the BB2 conformer also contributes to the experimental spectrum. The low-intensity band at $782 \mathrm{~cm}^{-1}$, representing symmetric and asymmetric $\mathrm{P}-\mathrm{O}$ alkoxy stretching, also provides evidence of the BB1 conformer's role as the dominant contributor to the experimental spectrum. The BB2 conformer, lying only $0.2 \mathrm{~kJ} / \mathrm{mol}$ (MP2) above the ground-state BB1 structure, is predicted to provide a nearly equal contribution to the experimental spectrum. The BB3 conformer lies $17.5 \mathrm{~kJ} / \mathrm{mol}$ (MP2) above the ground-state conformer and is therefore not a likely contributor to the observed spectrum. Indeed, the theoretical linear IR spectrum associated with the BB3 conformer differs greatly from the measured IRMPD action spectrum. Bands at 754 and $918 \mathrm{~cm}^{-1}$ represent asymmetric $\mathrm{P}-\mathrm{O}$ alkoxy stretching modes, while the band at $779 \mathrm{~cm}^{-1}$ corresponds to symmetric $\mathrm{P}-\mathrm{O}$ alkoxy stretching. Symmetric and asymmetric $\mathrm{P}=\mathrm{O}$ stretches appear at 1096 and $1224 \mathrm{~cm}^{-1}$, and bands at 1035 and $1142 \mathrm{~cm}^{-1}$ are produced by a combination of $\mathrm{P}=\mathrm{O}$ and $\mathrm{P}-\mathrm{O}-\mathrm{C}$ stretching modes.

\section{Theoretical Systems: [DEP] and [DEP - H+Na]}

In addition to the four ionic systems investigated experimentally, a theoretical study of the neutral complexes [DEP] and [DEP $-\mathrm{H}+\mathrm{Na}$ ] was pursued in an attempt to infer structural properties of these biologically relevant model systems. Theoretical spectra for the three most stable conformers for these systems are shown in ESM Figures $3 \mathrm{~S}$ and $5 \mathrm{~S}$, respectively.

Only minor variations in the spectral features, in terms of both the relative intensities and band positions, are found for the three low-energy conformers of [DEP], making the differentiation of these species difficult. Shifts in the band positions are the largest for the four most intense features, which occur at $883,992,1062$, and $1297 \mathrm{~cm}^{-1}$ for the ground-state $\mathrm{C} 1$ conformer, corresponding to the spectral region shown in Figure 3S and that measured for the ionic complexes, indicating that this region is the most useful for differentiating these species. The positions of each of these features differ for all three low-energy conformers, but vary by less than $16,11,7$, and $24 \mathrm{~cm}^{-1}$, respectively. The highintensity band at $1060 \mathrm{~cm}^{-1}$ corresponds to asymmetric $\mathrm{C}-\mathrm{O}$ alkoxy stretching. The band at $993 \mathrm{~cm}^{-1}$ corresponds to asymmetric $\mathrm{C}-\mathrm{C}$ stretching, while the $\mathrm{P}-\mathrm{O}$ and $\mathrm{P}=\mathrm{O}$ stretches are observed at 883 and $1295 \mathrm{~cm}^{-1}$, respectively. Three additional low-intensity features are found in the highfrequency region (not shown in the figure) at $~ 3050,3137$, and $3832 \mathrm{~cm}^{-1}$ for the ground-state $\mathrm{C} 1$ conformer, corresponding to various $\mathrm{C}-\mathrm{H}$ stretching modes of the alkoxy groups and the $\mathrm{O}-\mathrm{H}$ stretch, respectively. However, the positions of these features shift by less than $6 \mathrm{~cm}^{-1}$ for the $\mathrm{C} 2$ and $\mathrm{C} 3$ conformers, and thus are less useful for 
differentiating these species. Due to the narrow separation in energy between these conformers $(<4.3 \mathrm{~kJ} / \mathrm{mol})$, all three are likely populated at room temperature.

In stark contrast to the neutral [DEP] system, the [DEP $\mathrm{H}+\mathrm{Na}$ ] complexes are quite diverse in both their spectral features and their relative energetics. The high-intensity band at $1090 \mathrm{~cm}^{-1}$ corresponds to symmetric $\mathrm{P}=\mathrm{O}$ oxo and symmetric $\mathrm{P}-\mathrm{O}-\mathrm{C}$ alkoxy stretching modes, where the oxo and alkoxy stretches are asymmetric to one another. Outside of this common feature, the spectra of the three conformers are widely divergent. In the IR spectrum for the predicted ground-state conformer, a high-intensity band at $1193 \mathrm{~cm}^{-1}$ represents asymmetric $\mathrm{P}=\mathrm{O}$ stretching, while the corresponding bands are significantly blueshifted to $1290 \mathrm{~cm}^{-1}$ for the B2 structure, and to $1334 \mathrm{~cm}^{-1}$ for the T1 conformer. Additional bands include those representing asymmetric $\mathrm{P}-\mathrm{O}-\mathrm{C}$ alkoxy stretching (at 953, 936, and $922 \mathrm{~cm}^{-1}$ for the $\mathrm{B} 1, \mathrm{~B} 2$, and $\mathrm{T} 1$ structures, respectively) and asymmetric $\mathrm{P}-\mathrm{O}$ alkoxy stretching at 811,720 , and $715 \mathrm{~cm}^{-1}$ (conformers B1, $\mathrm{B} 2$ and $\mathrm{T} 1$, respectively). The large difference in relative energies suggests that the B1 conformer is likely to be the only structure present in a room-temperature distribution.

\section{Gas- Versus Solution-Phase IR Spectra}

Solution-phase infrared and Raman spectroscopic analyses of diethyl phosphate systems were previously completed by Stangret and Savoie, and their findings assist in the interpretation of the relevance of the theoretical neutral structures computed [34]. Raman spectroscopy of neutral DEP (in aqueous solution), as well as protonated DEP (in $4 \mathrm{M} \mathrm{HCl}$ ), bear a close resemblance to the experimental IRMPD spectrum of [DEP $-\mathrm{H}]^{-}$; each spectrum exhibits high-intensity bands in the region between 1080 and $1100 \mathrm{~cm}^{-1}$, as well as at $1288 \mathrm{~cm}^{-1}$. The high-intensity bands at 715 and $900 \mathrm{~cm}^{-1}$ of the IRMPD spectrum are blueshifted to $\sim 750$ and $943 \mathrm{~cm}^{-1}$ in the Raman spectrum. Experimental IR spectra do not correlate nearly as well with the IRMPD spectra as do the Raman spectra, likely due to similarities in excitation sources used by the two techniques. The highly monochromatic radiation used in Raman spectroscopy is better able to precisely excite vibrational and rotational modes of the DEP system than the light source used in traditional IR spectroscopy, which becomes especially important in a solvating environment where a variety of hydrated, deprotonated, neutral, and protonated species may be present. Of particular interest here is that the dominant form of DEP in both neutral and strongly acidic solutions remains the deprotonated species. Protonated DEP is also present in solution, as exhibited by the splitting of the band in the region between 1080 and $1100 \mathrm{~cm}^{-1}$, but persistence of the band at $1288 \mathrm{~cm}^{-1}$ suggests that a large population of deprotonated DEP is still present in strongly acidic solution.

Addition of sodium to the aqueous solution produces a Raman spectrum that is remarkably similar to that of the $[\text { DEP }-\mathrm{H}+2 \mathrm{Na}]^{+}$IRMPD spectrum. Bands at 782,943 , 1030,1080 , and $1225 \mathrm{~cm}^{-1}$ are found in each of these spectra. In addition, the $\mathrm{P}=\mathrm{O}$ bands at 1030 and $1080 \mathrm{~cm}^{-1}$ are the most intense bands in each spectrum, even though the relative intensities of the other bands are not as well matched in the Raman and IRMPD spectra. Overall, these results suggest that sodium cations interact with DEP in a bidentate fashion in neutral solutions. This is in agreement with the conclusions reached by Stangret and Savoie, who suggested that alkali metal cations interact in an electrostatic fashion with the phosphate groups in a relatively symmetric fashion with respect to the oxo oxygen atoms. In addition, they noted that increasing the $\mathrm{Na}^{+}$:DEP ratio from $2: 1$ to $18: 1$ results in essentially no change in the spectra, suggesting that at most two sodium cations interact with DEP.

\section{Structural and Spectral Trends in Diethyl Phosphate Esters: $[\mathrm{DEP}-\mathrm{H}]^{-}$to $[\mathrm{DEP}+\mathrm{H}]^{+}$}

Structural changes resulting from the addition of protons to deprotonated diethyl phosphate exhibit systematic variation in both the geometry of the nearly tetrahedral core structure as well as the location and staggering of the alkoxy side chains. The deprotonated phosphate ester is highly symmetrical, with staggered alkoxy side chains and a large $\angle \mathrm{OPO}$ bond angle $\left(125.7^{\circ}\right)$ due to electrostatic repulsion of the adjacent negatively charged oxo moieties. Addition of a proton, producing neutral [DEP], results in the reduction of the $\angle \mathrm{OPO}$ bond angle to $114.8^{\circ}$ and the rotation of an alkoxy side chain by $118.4^{\circ}$ about the $\angle \mathrm{OPOC}$ dihedral angle. The alkyl $\angle \mathrm{OPO}$ bond angles increase from $98.6^{\circ}$ to $101.4^{\circ}$. These changes, which are primarily the result of neutralization of the anionic dioxo core $\left(\mathrm{PO}_{2}{ }^{-}\right)$, result in a significant change in the overall conformation of the molecule. If the alkoxy chain carbons are participants in covalent bonding with other atoms, as in the case with a nucleic acid chain, the overall shape of the chain may become disrupted upon the binding of even a single proton. While oxo groups do not participate directly in covalent interactions with other nucleic acid backbone atoms, the resulting change in charge distribution that occurs when the deprotonated dioxo group is neutralized results in a significant change in the overall shape of the backbone. Structural changes for each species are accompanied by significant spectral changes. A blueshift is observed for the $\mathrm{P}=\mathrm{O}$ band, from 1280 to $1295 \mathrm{~cm}^{-1}$, and the relative intensity of this band is significantly decreased with respect to other spectral features. $\mathrm{P}-\mathrm{O}$ stretching is more significantly affected, as the addition of a proton results in a change in stretching modes as the electronic structure of the complex is modified, localizing more negative charge on the oxo oxygen atom while eliminating the charge on the overall complex. Symmetry is reduced upon the protonation of $[\mathrm{DEP}-\mathrm{H}]^{-}$, resulting in the emergence of additional 
carbon-carbon and carbon-oxygen stretching modes due to the greater bond diversity present in the system.

Binding of a second proton, resulting in the protonated $[\mathrm{DEP}+\mathrm{H}]^{+}$complex, causes further reduction of the hydroxyl $\angle \mathrm{OPO}$ bond angle $\left(104.9^{\circ}\right)$, while increasing the alkyl $\angle \mathrm{OPO}$ bond angles to $108.4^{\circ}$. The relative locations of the alkoxy side chain carbon atoms do not change appreciably, remaining in the same staggered configuration that was found for the neutral molecule. As a result of the increase in the alkyl $\angle \mathrm{OPO}$ bond angle, the adjacent alkoxy oxygen atoms become further displaced, from 2.48 to $2.51 \AA$, and a corresponding increase in the $\mathrm{C}-\mathrm{O}$ bond distance from 1.45 to $1.50 \AA$ accompanies these variations. Significant spectral changes also result from the addition of a proton to neutral [DEP], with fewer observable bands corresponding to fewer available stretching modes. $\mathrm{C}-\mathrm{O}$ stretching intensity is markedly reduced upon protonation, while $\mathrm{P}-\mathrm{O}$ and $\mathrm{P}-\mathrm{O}-\mathrm{H}$ stretching modes become the dominant spectral features.

While previous theoretical studies of counterion effects on nucleic acid chains have suggested that the presence of monovalent cations serves primarily as a stabilizing force counteracting the anionic repulsion felt by the phosphate backbone [35], our gas phase studies indicate that in the context of the nucleic acid phosphate backbone, protonation should modify the overall geometry of the chain by lengthening - or straightening - the backbone, making other interactions or reactions with the phosphate ester chain, or with the adjacent base residues, more favorable. As new techniques and theoretical methods become available, this may be an area warranting further investigation to determine the true nature of counterion effects on nucleic acid chains in the presence of solvent.

\section{Structural and Spectral Trends in Diethyl Phosphate Esters: $[\mathrm{DEP}-\mathrm{H}]^{-}$to $[\mathrm{DEP}+\mathrm{Na}]^{+}$}

Two separate pathways are described here that result in the formation of the $[\mathrm{DEP}+\mathrm{Na}]^{+}$ion. Both pathways involve the addition of a sodium cation and a proton, with the only difference being the order of addition. In the case of proton/ sodium cation addition, the initial proton addition was described in detail in the previous section. Subsequent sodium addition results in no change in alkoxy side chain orientation with respect to the phosphate moiety. The overall geometry of the complex is generally preserved, and only a small variation $(\sim 0.1 \AA)$ in the lengths of corresponding bonds between the two systems is present. These geometric modifications are even more evident when compared to the deprotonated [DEP - H] complex. A redshift from 1295 to $1240 \mathrm{~cm}^{-1}$ in the $\mathrm{P}=\mathrm{O}$ band is the only observable feature corresponding to both spectra. All other bands observed correspond to different stretching modes between the two systems, highlighting the impact of cationization on the geometry of the complex. The implications of these physical changes to phosphate ester geometry in a nucleic acid are again clear, suggesting that the binding of a cation to even a single anionic oxygen atom results in a physiologically significant change in the structure of the nucleic acid.

The second pathway involves sodium cation addition followed by the addition of a proton. The neutral [DEP $-\mathrm{H}+$ $\mathrm{Na}$ ] complex retains the symmetry present in the $[\mathrm{DEP}-\mathrm{H}]^{-}$ complex. The sodium cation binds in a bidentate fashion to both oxo moieties. The $\angle \mathrm{OPO}$ alkoxy bond angle increases slightly as the $\mathrm{P}-\mathrm{O}$ alkoxy bond length decreases, resulting in a negligible change in the overall $\mathrm{O}-\mathrm{O}$ (oxo-alkoxy) distance. Subsequent addition of a proton destroys the geometrical and charge symmetry of the system, resulting in an overall shortening of the $\mathrm{O}-\mathrm{O}$ distance. While individual spectral changes differ between the first and second pathways, the general theme of broad, overall change is observed in each spectra.

\section{Structural and Spectral Trends in Diethyl Phosphate Esters: $[\mathrm{DEP}-\mathrm{H}]^{-}$to $[\mathrm{DEP}-\mathrm{H}+2 \mathrm{Na}]^{+}$}

Formation of $[\mathrm{DEP}-\mathrm{H}+2 \mathrm{Na}]^{+}$occurs as a result of the addition of two $\mathrm{Na}^{+}$cations to [DEP $\left.-\mathrm{H}\right]^{-}$. As discussed above, the binding of a single $\mathrm{Na}^{+}$cation produces only small changes in the overall geometry of the phosphate ester. As observed in the other cases investigated here, the addition of the second cation destroys the symmetry of the complex, resulting in significant structural changes to the system. These changes include the adoption of a staggered configuration, with the adjacent alkoxy chain rotated away from the sodium cation, along with a change in phosphate $\mathrm{P}-\mathrm{O}$ bond lengths and angles that ultimately results in a marked decrease in the $\mathrm{O}-\mathrm{O}$ (oxo-alkoxy) distance. Unlike the other systems described earlier, a great deal of correlation is exhibited between spectra of the neutral and cationic complexes. A redshift in bands at 811,953 and $1090 \mathrm{~cm}^{-1}$ to 782,943 and $1055 \mathrm{~cm}^{-1}$ is accompanied by a blueshift of the $\mathrm{P}=\mathrm{O}$ band, from 1193 to $1225 \mathrm{~cm}^{-1}$. Each band corresponds to various types of $\mathrm{P}-\mathrm{O}$ stretching, as described in the previous sections.

\section{Conclusions}

IRMPD of deprotonated, protonated, and sodium-cationized diethyl phosphate complexes produces distinct spectra allowing for the accurate description of structural features. Activation occurs through a variety of pathways, sometimes through a single dissociation channel, and for other complexes through several channels. Assignment of stretching modes to the bands observed is possible through the use of theoretical linear IR spectra produced from geometryoptimized structures derived from DFT calculations at the B3LYP/6-31G(d) and B3LYP/6-31G(d,p) levels of theory. Optimizations and IR spectra computed using the larger basis set, $6-31 \mathrm{G}(\mathrm{d}, \mathrm{p})$, produce a slightly better fit to the experimental spectra. The reproduction of the experimental IRMPD spectra is best when a scaling factor of 0.9613 is 
employed for deprotonated DEP, and there is no scaling of the computed frequencies for protonated and sodiumcationized DEP. Furthermore, single point energy calculations are completed in an effort to compare and contrast DFT techniques (B3LYP and B3P86) with MP2 theory. Each calculation is performed using a $6-311+\mathrm{G}(2 \mathrm{~d}, 2 \mathrm{p})$ basis set, and includes zero point energy corrections. The addition of protons and/or sodium cations significantly impacts the overall geometry of each complex, suggesting that the phosphate ester backbones of nucleic acids in the context of a physiological environment will be similarly affected by proton or sodium cation binding. These behavioral tendencies may help to explain, and to further elucidate, low-level mechanisms and physical properties of DNA and RNA strands undergoing regulatory processes in the cellular environment.

\section{Acknowledgements}

This work is supported by the National Science Foundation, grants PIRE-0730072 and CHE-0911191. We also wish to thank Wayne State University C\&IT for computer time. N. O.F. also thanks the WSU Honors program for additional financial support. This work is also part of the research program of the FOM, which is financially supported by the Nederlandse Organisatie voor Wetenschappeklijk Onderzoek (NWO). The skillful assistance of the FELIX staff is gratefully acknowledged.

\section{Open Access}

This article is distributed under the terms of the Creative Commons Attribution Noncommercial License which permits any noncommercial use, distribution, and reproduction in any medium, provided the original author(s) and source are credited.

\section{References}

1. Klug, W.S., Cummings, M.R.: Concepts of genetics, 7th edn, p. 7. Prentice Hall, Upper Saddle River, NJ (2003)

2. Eichhorn, G.L., Butzow, J.J., Shin, Y.A.: Some effects of metal ions on DNA structure and genetic information transfer (Proceedings of the International Symposium of Biomolecular Structure Interactions). $J$. Biosci. 8(Suppl), 527-535 (1985)

3. Alberts, B., Johnson, A., Lewis, J., Raff, M., Roberts, K., Walter, P.: Molecular biology of the cell, 4th edn, p. 624. Garland Science, New York, NY (2002)

4. Eichhorn, G.L.: In: Eichhorn, G.L., Marzilli, L.G. (eds.) Advances in inorganic biochemistry, vol 3, pp. 1-2. Elsevier, New York (1981)

5. Manning, G.S.: The molecular theory of polyelectrolyte solutions with applications to the electrostatic properties of polynucleotides. Q. Rev. Biophys. 11, 179-246 (1978)

6. Hud, N.V., Feigon, J.: Localization of divalent metal ions in the minor groove of DNA A-tracts. J. Am. Chem. Soc. 119, 5756-5757 (1997)

7. Shui, X., McFail-Isom, L., Hu, G.G., Williams, L.D.: The B-DNA dodecamer at high resolution reveals a spine of water on sodium. Biochemistry 37, 8341-8355 (1998)

8. Tereshko, V., Minasov, G., Egli, M.: A "Hydrat-Ion" spine in a B-DNA minor groove. J. Am. Chem. Soc. 121, 3590-3595 (1999)
9. Young, M.A., Jayaram, B., Beveridge, D.L.: Intrusion of counterions into the spine of hydration in the minor groove of B-DNA: fractional occupancy of electronegative pockets. J. Am. Chem. Soc. 119, 59-69 (1997)

10. Cheatham, T.E., Kollman, P.A.: Molecular dynamics simulation of nucleic acids. Ann. Rev. Phys. Chem. 51, 435-471 (2000)

11. Drew, H.R., Dickerson, R.E.: Structure of a B-DNA dodecamer. III. Geometry of hydration. J. Mol. Biol. 151, 535-556 (1981)

12. Chiu, T.K., Kaczor-Grzeskowiak, M., Dickerson, R.E.: Absence of minor groove monovalent cations in the crosslinked dodecamer C-G-CG-A-A-T-T-C-G-C-G. J. Mol. Biol. 292, 589-608 (1999)

13. Denisov, V.P., Halle, B.: Sequence-specific binding of counterions to B-DNA. Proc. Nat. Acad. Sci. U.S.A. 97, 629-633 (2000)

14. Shui, X., Sines, C.C., McFail-Isom, L., VanDerveer, D., Williams, L. D.: Structure of the potassium form of CGCGAATTCGCG: DNA deformation by electrostatic collapse around inorganic cations. Biochemistry 37, 16877-16887 (1998)

15. Stellwagen, N.C., Magnusdottir, S., Gelfi, C., Righetti, P.G.: Preferential counterion binding to A-Tract DNA oligomers. J. Mol. Biol. 305, 1025-1033 (2001)

16. Woods, K.K., McFail-Isom, L., Sines, C.C., Howerton, S.B., Stephens, R.K., Williams, L.D.: Monovalent cations sequester within the A-tract minor groove of $[(\mathrm{dCGCGAATTCGCG})] 2$. J. Am. Chem. Soc. 122, 1546-1547 (2000)

17. Hamelberg, D., McFail-Isom, L., Williams, L.D., Wilson, W.D.: Flexible structure of DNA: ion dependence of minor-groove structure and dynamics. J. Am. Chem. Soc. 122, 10513-10520 (2000)

18. Feig, M., Pettitt, B.M.: Sodium and chlorine ions as part of the DNA solvation shell. Biophys. J. 77, 1769-1781 (1999)

19. Beveridge, D.L., McConnell, K.J.: DNA structure: what's in charge? $J$. Mol. Biol. 304, 803-820 (2000)

20. Auffinger, P., Westhof, E.: Water and ion binding around RNA and DNA (C, G) oligomers. J. Mol. Biol. 300, 1113-1131 (2000)

21. Ruan, C., Huang, H., Rodgers, M.T.: Modeling metal cationphosphate interactions in nucleic acids in the gas phase via alkali metal cation-triethyl phosphate complexes. J. Phys. Chem. A. 111, 13521-13527 (2007)

22. Ruan, C., Huang, H., Rodgers, M.T.: A simple model for metal cationphosphate interactions in nucleic acids in the gas phase: alkali metal cations and trimethyl phosphate. J. Am. Soc. Mass Spectrom. 19, 305314 (2008)

23. Ruan, C., Rodgers, M.T.: Modeling metal cation-phosphate interactions in nucleic acids: activated dissociation of $\mathrm{Mg}^{+}, \mathrm{Al}^{+}, \mathrm{Cu}^{+}$, and $\mathrm{Zn}^{+}$ complexes of triethyl phosphate. J. Am. Chem. Soc. 131, 10918-10928 (2009)

24. Nei, Y-w., Akinyemi, T.E., Steill, J.D., Oomens, J., Rodgers, M.T.: Infrared multiphoton dissociation action spectroscopy of protonated uracil and thiouracils: effects of thioketo-substitution on gas-phase conformation. Int J Mass Spectrom. 297, 139-151 (2010)

25. Valle, J.J., Eyler, J.R., Oomens, J., Moore, D.T., van der Meer, A.F.G., von Heldon, G., Meijer, G., Hendrickson, C.L., Marshall, A.G., Blakney, G.T.: Free electron laser-Fourier transform ion cyclotron resonance mass spectrometry facility for obtaining infrared multiphoton dissociation spectra of gaseous ions. Rev. Sci. Instrum. 76, 023103 (2005)

26. Polfer, N.C., Oomens, J., Moore, D.T., von Helden, G., Meijer, G., Dunbar, R.C.: Infrared spectroscopy of phenylalanine $\mathrm{Ag}(\mathrm{I})$ and $\mathrm{Zn}(\mathrm{II})$ complexes in the gas phase. J. Am. Chem. Soc. 128, 517-525 (2006)

27. Polfer, N.C., Oomens, J.: Reaction products in mass spectrometry elucidated with infrared spectroscopy. Phys. Chem. Chem. Phys. 9, 3804-3817 (2007)

28. Oepts, D., van der Meer, A.F.G., van Amersfoort, P.W.: The freeelectron-laser user facility FELIX. Infrared Phys. Technol. 36, 297-308 (1995)

29. Hypercube Inc.: HyperChem Computational Chemistry Software Package, Version 5.0. Hypercube Inc., Gainesville, FL (1997)

30. Frisch, M.J., Trucks, G.W., Schlegel, H.B., Scuseria, G.E., Robb, M. A., Cheeseman, J.R., Montgomery, J.A., Vreven, Jr., T., Kudin, K. N., Burant, J.C., Millam, J.M., Iyengar, S.S., Tomasi, J., Barone, V., Mennucci, B., Cossi, M., Scalmani, G., Rega, N., Petersson, G.A., Nakatsuji, H., Hada, M., Ehara, M., Toyota, K., Fukuda, R., Hasegawa, J., Ishida, M., Nakajima, T., Honda, Y., Kitao, O., Nakai, H., Klene, M., Li, X., Knox, J.E., Hratchian, H.P., Cross, J. B., Adamo, C., Jaramillo, J., Gomperts, R., Stratmann, R.E., 
Yazyev, O., Austin, A.J., Cammi, R., Pomelli, C., Ochterski, J.W., Ayala, P.Y., Morokuma, K., Voth, G.A., Salvador, P., Dannenberg, J.J., Zakrzerski, V.G., Dapprich, S., Daniels, A.D., Strain, M.C., Farkas, O., Malick, D.K., Rabuck, A.D., Raghavachari, K., Foresman, J.B., Ortiz, J.V., Cui, Q., Baboul, A.G., Clifford, S., Cioslowski, J., Stefanov, B.B., Liu, G., Liashenko, A., Piskorz, P., Komaromi, I., Martin, R.L., Fox, D.J., Keith, T., Al-Laham, M.A., Peng, C. Y., Nanayakkara, A., Challacombe, M., Gill, P.M.W., Johnson, B., Chen, W., Wong, M.W., Gonzalez, C., Pople, J.A.: Gaussian 03, Revision B.03. Gaussian, Inc., Wallingford, CT, (2004)

31. Wong, M.W.: Vibrational frequency prediction using density functional theory. Chem. Phys. Lett. 256, 391-399 (1996)
32. Correia, C.F., Balaj, O.P., Scuderi, D., Maitre, P., Ohanessian, G.: Vibrational signatures of protonated, phosphorylated amino acids in the gas phase. J. Am. Chem. Soc. 130, 3359-3370 (2008)

33. Prell, J.S., O'Brien, J.T., Williams, E.R.: IRPD spectroscopy and ensemble measurements: effects of different data acquisition and analysis methods. J. Am. Soc. Mass Spectrom. 21, 800-809 (2010)

34. Stangret, J., Savoie, R.: Vibrational spectroscopic study of the interaction of metal ions with diethyl phosphate, a model for biological systems. Can. J. Chem. 12, 2875-2883 (1970)

35. Felsenfeld, G., Miles, H.T.: The physical and chemical properties of nucleic acids. Ann. Rev. Biochem. 36, 407-448 (1967) 